\title{
The Transformer Aircraft: A Multi-Mission Unmanned Aerial Vehicle Capable of Symmetric and Asymmetric Span Morphing
}

\author{
Rafic M. Ajaj1,2 and Girish K. Jankee ${ }^{2}$ \\ ${ }^{1}$ Mechanical Engineering Department, United Arab Emirates University, Al Ain, UAE \\ ${ }^{2}$ Aeronautics and Astronautics, University of Southampton, Southampton, UK, SO17 1BJ
}

\begin{abstract}
This paper presents the development and extensive testing of the Transformer aircraft, a multimission UAV capable of symmetric and asymmetric span morphing. The UAV utilises a novel actuation system based on a rack and pinion mechanism to achieve span extensions up to $50 \%$. The Transformer can morph symmetrically to enhance flight performance and asymmetrically to provide roll control. Extensive mechanical testing followed by wind-tunnel testing in the RJ Mitchell Wind-tunnel at the University of Southampton were conducted to ensure structural integrity and assess the behaviour of the UAV. Finally, a series of flight-testing were performed and the flight mechanics aspects associated with both symmetric and asymmetric span morphing were investigated.
\end{abstract}

\section{Introduction}

Large wingspans offer enhanced flight performance but reduce the manoeuvrability margin. On the other hand, low aspect ratio wings offer higher margins of agility but lack the aerodynamic efficiency (Barbarino et al., 2011). A span morphing wing can combine the advantages of both design allowing one aircraft to effectively perform different types of missions (Ajaj et al., 2016a). The idea of span morphing is not new. Ivan Makhonine, a Russian expatriate, developed one of the earliest span morphing wing designs. The MAK-10 was an aircraft that flew in the 1930s with a telescopic span morphing wing. He used pneumatic actuators to morph the telescopic wing and his design was capable of achieving up to $60 \%$ span extension (Weisshaar, 2006). In recent years, there have been some promising work on span morphing wings. For example, Blondeau et al. (2007) developed a telescopic wing and they used hollow fiberglass shells to preserve the aerofoil shape and reduce storage size of the wing. To reduce the weight, they used inflatable actuators instead of rigid spars to support the aerodynamic loads on the wing. On the other hand, Bae et al. (2005) conducted static and dynamic studies on the wing of a long-range cruise missile and identified some of the difficulties associated with the design of a morphing wing capable of span change. Their studies concluded a drag reduction of $25 \%$ and a range increase of $30 \%$. Furthermore, the authors developed a number of wing designs that facilitate changing the span. These designs include the Zigzag Wingbox concept (Ajaj et al., 2013), the Compliant Spar concept (Ajaj et al., 2014), and the Gear driveN Autonomous 1

*Rafic Ajaj, Assistant Professor of Aerospace Engineering, UAEU, raficajaj@uaeu.ac.ae Girish Jankee, PhD Student, Aerodynamics and Flight Mechanics Group, UoS, g.jankee@ soton.ac.uk 
Twin Spar (GNATSpar) (Ajaj et al., 2016b). Most of the concepts developed by Ajaj et al. (2013, 2014 and 2016b) used a hybrid structural design philosophy where the wing structure is at the same time the mechanism and the actuator. The structure was then covered by flexible material (mainly elastomeric) to provide and maintain the aerodynamic profile. A more extensive review on span morphing technology (applications and concepts) for both fixed-wing and rotary-wing aircraft is given in Barbarino et al. (2011). This paper aims to experimentally assess the impact of span morphing on the flight performance (when operated symmetrically) and on its ability to enhance roll control authority (when operated asymmetrically). Therefore, an electrically powered, span morphing mini-UAV is designed, built and tested. A telescopic mechanism, that facilitates both symmetric and asymmetric span morphing, is developed. The paper provides an overview on the design, sizing and manufacturing of the UAV and it details the wind-tunnel and flight testing performed.

\section{The Morphing UAV}

\section{A. UAV's Configuration}

A conventional UAV configuration was selected to simplify the integration of the span morphing wing and to minimise unwanted couplings between the different axes. In addition, a conventional UAV configuration may allow scaling some of the results of this study to large aircraft with similar conventional configurations. This scaling might not be feasible if unconventional UAV configurations (such as flying wings) were used. The UAV's maximum take-off weight must not exceed $15 \mathrm{~kg}$ and therefore it will be electrically powered using one powerful electric motor driven by a series of on-board batteries. The UAV's configuration is shown in Figure 1. A tractor propulsion system (attached to the nose of the UAV) is selected due to its ability to reduce prop strike on take-off whilst allowing for a lighter single-boom empennage configuration. A conventional, fixed tricycle landing gear arrangement is used where the nose and main landing gears are mounted to the bulkheads of the fuselage to minimise the impact of landing loads on the span morphing wing and maximise the internal volume of the fuselage (central wingbox) to house the morphing mechanism/actuation system. The baseline wingspan, when fully retracted, is $2 \mathrm{~m}$. 


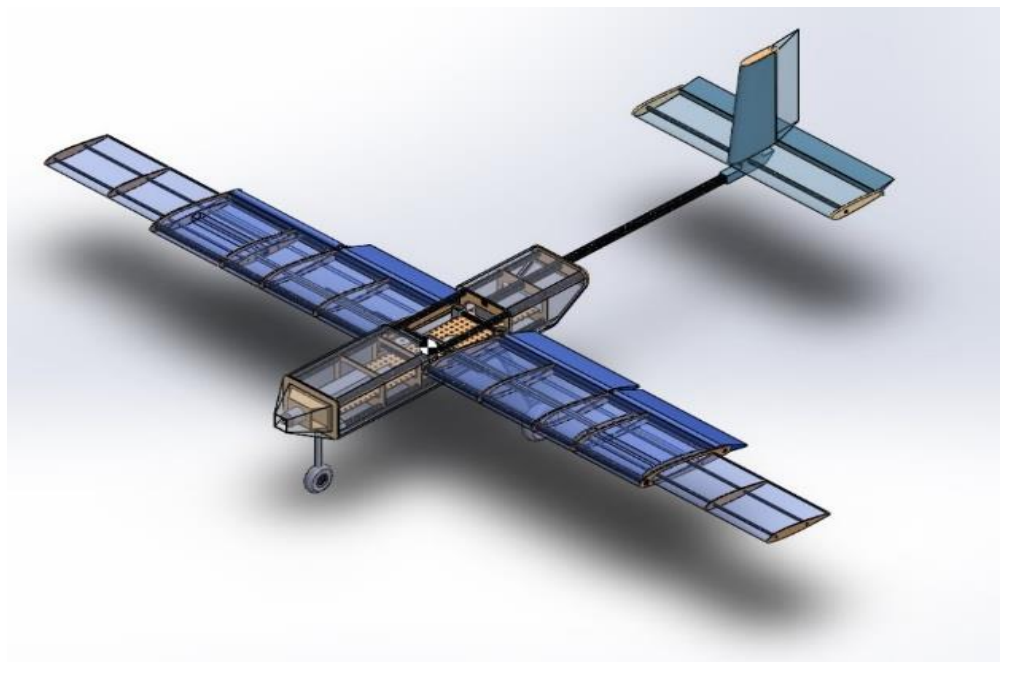

Figure 1: The UAV Platform.

\section{B. Morphing mechanism}

There is a number of span morphing mechanisms available in literature. However, telescopic span morphing mechanism are the most popular due to their relatively simple design, high reliability and durability, and minimal actuation requirements. Telescopic mechanisms can achieve high morphing rate due to their low actuation force requirement (when compared with non-telescopic or hybrid telescopic (those covered by elastomeric material)) which is necessary for utilising span extension for roll control. Therefore, it was decided to utilise a telescopic mechanism to vary the wingspan. To achieve both symmetric and asymmetric morphing, two independent actuators will be used. A study by Ajaj et al. (2012 and 2014) concluded that for flight performance and roll control purposes only span extensions of up to $50 \%$ are required. Therefore, this paper focuses on span extension (symmetric and asymmetric) of up to 50\% even though the span morphing mechanism that is developed here allows achieving span extension up to $100 \%$. The maximum wingspan studied here is $3 \mathrm{~m}$ ( $50 \%$ extension). To maximise the effectiveness of the vehicle (in case of jamming or failure of the morphing mechanism), it must be able to fly effectively throughout all the flight phases (take-off, cruise/loiter and landing) with the wing fully retracted which necessitates the need for flaps and ailerons. Since the extension is stored in the main wing when fully retracted, both the flaps and ailerons are attached to the fixed partition (non-morphing part) of the wing. This will ensure that that the extension/retraction path is kept clear regardless of the wing configuration as shown in Figure $2 \mathrm{a}$ and $\mathrm{b}$. To simplify the integration of the morphing mechanism with the wing, wing dihedral, sweep, taper and twist were avoided and a mid-wing configuration was selected to easily house the actuation system needed. Due to the telescopic nature of the morphing mechanism used (discussed in the next section), the extending part 
of the wing has a smaller chord and is set at a geometric incidence angle (to prevent tip stall) relative to the main wing section as shown Figure 2c.

\section{Design, Manufacturing and Integration}

\section{i. Wing Geometry}

This paper focuses on assessing the impact of span morphing on the aerodynamics and flight mechanics of the UAV. Therefore, a rectangular, unswept, untwisted wing with no dihedral is selected. The UAV is expected to take-off from a $50 \mathrm{~m}$ long grassy runway. The UAV must be able to take-off with wing fully retracted and flap fully deployed $\left(30^{\circ}\right)$. The main wing geometry was defined mainly by the take-off performance of the UAV. The chord of the baseline wing (without the flaps) was chosen to be $450 \mathrm{~mm}$, so that it is long enough to accommodate the wing extension to provide the UAV with a sufficient lifting surface area for take-off, but also to ensure a relatively high aspect ratio in order to minimise induced drag and to achieve a more efficient spanwise lift distribution. Table 1 presents the geometrical characteristics of the main wing. Due to the size of the ailerons and the flaps, as well as the presence of spars in the main wings, the chord of the wing extensions was limited to $250 \mathrm{~mm}$. Each wing extension has a length of 780 $\mathrm{mm}$, out of which $280 \mathrm{~mm}$ represents an overlapping section with the main wing. Hence, the maximum possible extension is $50 \%$ of the main wingspan $(2 \mathrm{~m})$. Figure 2 illustrates the wing in fully retracted and fully extended configurations, along with the corresponding dimensions.

Table 1: Geometrical Properties of the Wings

\begin{tabular}{lcccc}
\hline & $\mathbf{S ~ ( \mathbf { m } ^ { 2 } )}$ & $\mathbf{b}(\mathbf{m})$ & Aspect Ratio & $\mathbf{c}(\mathbf{m})$ \\
\hline Fully Retracted Configuration & 1.18 & 2.0 & 3.40 & 0.590 \\
\hline Fully Extended Configuration & 1.43 & 3.0 & 6.30 & 0.590 and 0.250 \\
\hline
\end{tabular}

The NACA 23012 aerofoil was selected due to its desirable stall characteristics and its relatively large thickness to chord ratio needed to house the extension as shown in Figure 2c. 3D simulations using XFLR5 (Deperrois, 2010) demonstrated that the stall angle of the extended wing is around $18-19^{\circ}$ at Reynolds number of 600,000 at the wing root and 350,000 at the wing tip. This indicates that the extension is more likely to stall before the main wing. Therefore, the geometric incidence of the main wing (relative to the horizontal fuselage datum) is set at $6^{\circ}$ while that of the extension is set at $4^{\circ}$ to ensure that the main wing stall before the extension to prevent to prevent the UAV from spinning. The $6^{\circ}$ incidence of the main wing relative to the body reduces the pitch attitude of the UAV throughout flight. The UAV's optimal cruising speed is $15 \mathrm{~m} / \mathrm{s}$ but it can fly at up to $25 \mathrm{~m} / \mathrm{s}$ without any permanent structural failure. 


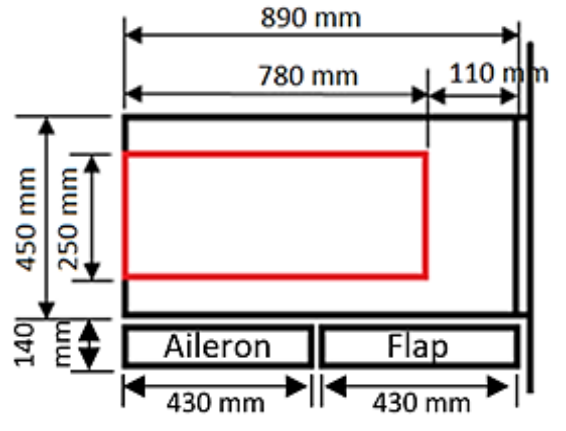

a. Wing semi-span at full retraction.

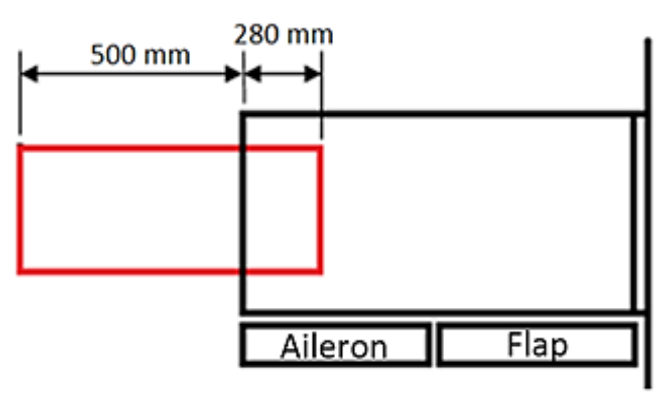

b. Wing semi-span at full extension.

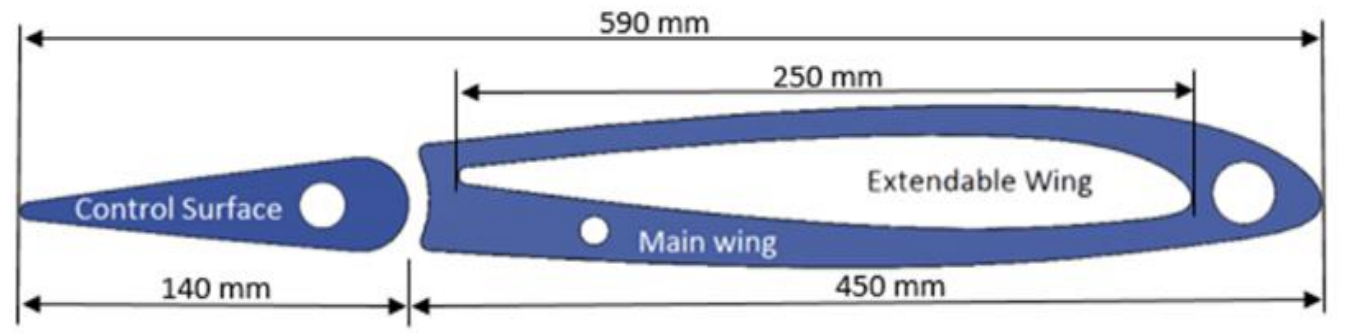

c. Cross-sectional area of the morphing wing.

Figure 2: Schematic demonstrating the retracted and extended wing configurations.

\section{ii. Ailerons and Flaps Geometries}

The main factor during ailerons sizing was providing sufficient roll authority when the wings are fully extended (largest inertia about the longitudinal axis of the plane and largest roll damping). To simplify the wing design, the flaps and the ailerons have the same span and occupy the entire span of the main wing. The aileron/flap chord was set to $30 \%$ of the main wing chord to achieve a roll helix angle of 0.09 radians (usually set for fighters).

\section{iii. Wing Structural Requirement}

In terms of materials, ribs were made from Birch plywood, spars from carbon fibre reinforced epoxy and the skin Styrofoam. To maximise the bending and torsional stiffness of the main wing and allow for smooth loads transfer between the extension and the main wing, a two spars structural configuration was selected for the main wing. It was assumed that the two spars bear all the loading on the wing (no contribution from the foam skin). The front spar, located at $6 \%$ of the main wing's chord, withstands $75 \%$ of the loads while the rear spar, located at $77 \%$ of the main wing's chord. The sizing scenario for the spars is determined when the aircraft flying at its critical speeds (cruise speed) with the flaps up encounters a vertical gust of 50 feet per second with the wing fully extended resulting in a load factor of around 4.5g (CASR Part 21, 2011). A further constraint was considered when sizing the spars to limit the out-of-plane/bending deflections to 2 $\mathrm{mm}$ in the region where the main wing and the extensions overlap. This is mainly to avoid excessive 
bending and hence jamming of the mechanism. The front spar has an outer diameter is $20.8 \mathrm{~mm}$ and the inner diameter is $18.0 \mathrm{~mm}$ while the rear spar has an outer diameter of $15.5 \mathrm{~mm}$ and an inner diameter of $12.7 \mathrm{~mm}$. The rear spar also acts as the hinge line for the flaps and ailerons as shown in Figure 3 . The rib spacing of the main wing is around $215 \mathrm{~mm}$ but reduces to $170 \mathrm{~mm}$ in the region where the main wing and the extension overlaps. Similarly, the extension (on each side) has two spars. The front spar located at $10 \%$ of the extension's chord while the rear spar located at $63 \%$ of the extension's chord. The foam of the extension is not hollow as with main wing (Figure 2c), it only has holes to allow for the extension spars. There are two ribs attached to the extension one at each of its ends to clamp the spars to the foam skin. Wooden casings were used to avoid bonding the servos directly to the ribs as shown in Figure 3.

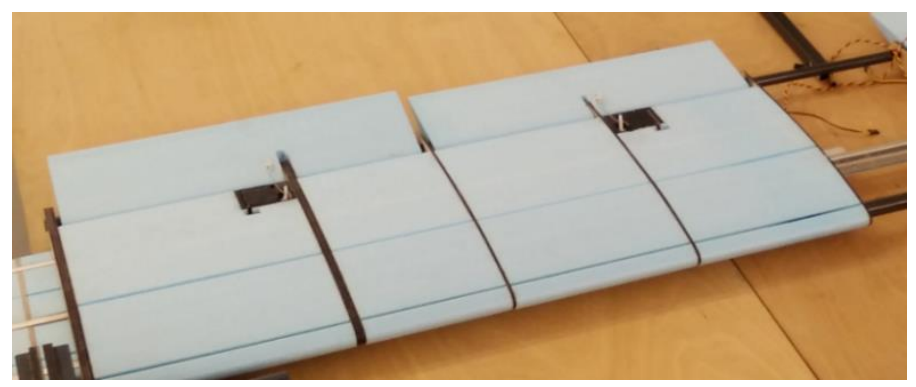

Figure 3: Wing assembly (Lower Surface).

\section{iv. Fuselage, Empennage and Landing Gear}

The fuselage houses the actuation mechanism of the span extension and therefore a simple fuselage design is preferred. Bulkheads, spars and ribs were used for load carrying as show in Figure 4. A plywood floor and a foam skin with a removable roof section were also incorporated but were non-load carrying.

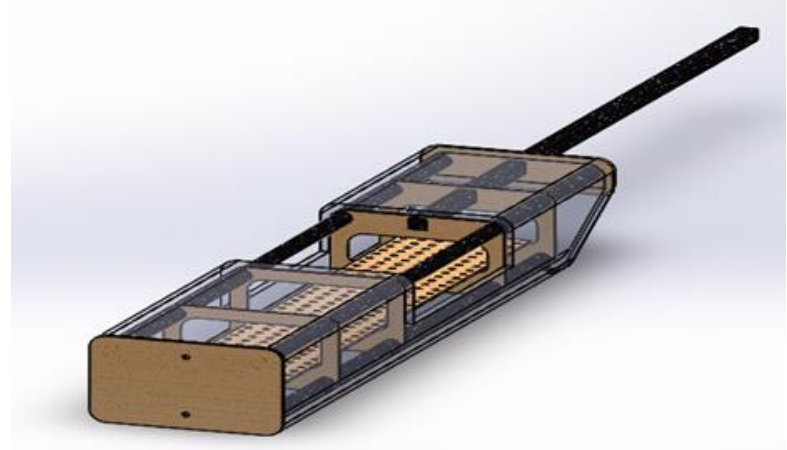

Figure 4: CAD Model of fuselage structure.

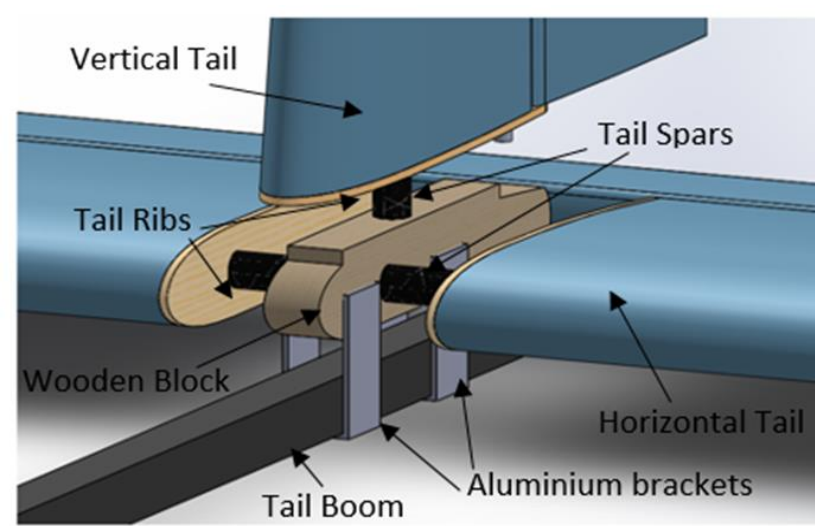

Figure 5: Exploded view of the tail structure. 
Four spars run through the length of the fuselage, the upper two being $1 \mathrm{~m}$ in length and the lower two being $800 \mathrm{~mm}$ in length (the cut-out increases ground clearance for take-off rotation). The spars were placed in each corner of the fuselage front bulkhead and would resist in-plane loads. Three bulkheads were used, one at the front and two at the rear of the fuselage spars (two rear bulkheads were required due to the discrepancy in spar length) and wooden ribs were located throughout the fuselage to maintain torsional stiffness. The fuselage spars also provide mounting points for the landing gear and wing. The fuselage's spars are carbon fibre reinforced epoxy whereas the, bulkheads and ribs are made from laser cut plywood. Wing and landing gear mounts were manufactured from aluminium, as these components would experience large loads. Due to the incidence setting of the wings, the leading-edge spar of the wing is around $40 \mathrm{~mm}$ higher than the trailing edge spar. Therefore, the wing spar was attached to the top fuselage spars, while the rear wing spar was attached to the bottom fuselage spars. The attachment between the wing and fuselage spar was achieved using aluminium square channel, with a width of $30 \mathrm{~mm}$ and $2 \mathrm{~mm}$ thick walls as shown in Figure 6. These channels were then bonded to the fuselage ribs resulting in a robust load path between the wing and fuselage. The $4.5 \mathrm{~g}$ scenario was simulated in Solidworks SimulationXpress and showed sufficient structural integrity of the UAV and a large safety margin for these attachments. Each attachment has a mass of 40 grams.
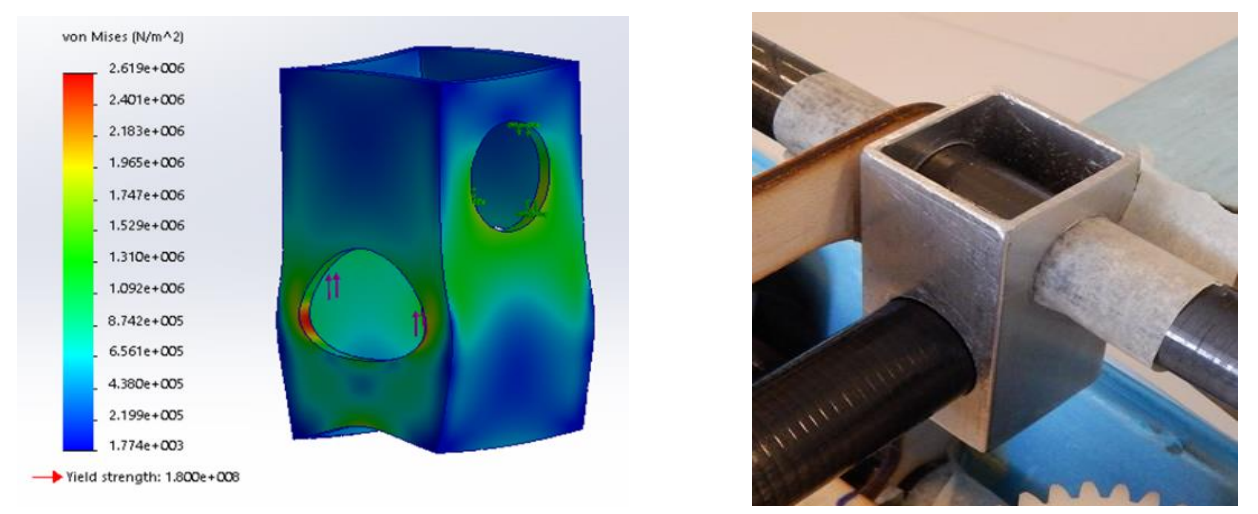

Figure 6: The aluminium wing-fuselage attachment.

The nose gear consisted of a square aluminium channel mounting, and a single aluminium strut with a damper. The main landing gear consisted of an aluminium U-channel mounting. The transformer has a conventional empennage configuration connected to the fuselage using a single boom. The structural joint connecting the horizontal and vertical tail spars to the boom must be rigid enough to prevent the vertical and horizontal tails from any relative motion. Therefore, a structural block of the same aerodynamic profile as the horizontal stabilizer was designed as shown in Figure 5. The spar of the horizontal tail passes through the block and root-end of the vertical tail's spar sit in. This block splits the main horizontal stabilizer into 
two halves and a rib bonded onto each free end. The ribs were laser cut from $3 \mathrm{~mm}$ plywood whilst the tail surfaces were cut from Styrofoam. The materials were chosen due to their lightweight properties and ability to be easily and strongly bonded together. The tail ribs allowed a sufficiently large and solid connection between the ribs and the block which were later bonded with an epoxy adhesive. A flat area was designed to extend a small distance above the top of the horizontal stabilizer to ensure a flat surface was available on which a vertical stabilizer rib was bonded. The block was made from wood to withstand maximum tail loads. An exploded CAD view of the tail structure is shown in Figure 5. The tail's boom has a hollow square cross-section whose depth is $20 \mathrm{~mm}$ and thickness is $1.5 \mathrm{~mm}$.

\section{v. Morphing Mechanism}

The Transformer is capable of symmetric and asymmetric span extension. The asymmetric extension augments the performance of conventional ailerons in providing roll control. Therefore, the morphing rate is of paramount importance when designing the morphing mechanism. To reduce the weight penalty associated with the morphing mechanism, both racks and pinions are chosen to be made from Delrin due to its high specific strength. An electric motor drives the pinion which will translate the rack across the span. The absence of a worm gear with low lead angle and a spur gear (as described by Ajaj et al. (2016b)) implies that the morphing mechanism is not self-locking and will require continuous torque from the motor to keep it locked in the desired position. The rack has a width of $12 \mathrm{~mm}$, a height of $18 \mathrm{~mm}$ and the length of the rack is $500 \mathrm{~mm}$ for $50 \%$ span morphing. Two of the actuation mechanism described above are needed to allow extending the right and left wings independently as shown in Figure $7 \mathrm{a}$ and $\mathrm{b}$. The Delrin racks are housed (using bonding) in aluminium C-channels to increase their stiffness (reduce bending deflection of the extension to avoid jamming). The channels connect the morphing partition (extension) directly to the mechanisms located in the root region to transfer the linear motion of the rack into span extension and to transfer the aerodynamic loads from the morphing partition (extension) to the wing-fuselage bulkhead ribs. Since the racks/channels will be translating in the spanwise direction, they can't be directly fixed to the bulkheads. Therefore, rails are required to ensure that the racks have only one degree of freedom and transfer the loads from the racks to the bulkheads. Groove ball bearing drawer runners, which are commonly used in drawer applications, were used. The rails, which are made from galvanized steel, are capable of carrying up to a $10 \mathrm{~kg}$ load (each) and can slide both ways. The ball bearings ensure smoother span morphing and the whole structure provides most of the bending support to the rack. The rail dimensions are $17 \mathrm{~mm}$ wide, $10 \mathrm{~mm}$ high and $432 \mathrm{~mm}$ long. For the arrangement of the linear actuator components, the rack is bonded to a long aluminium $\mathrm{C}$ channel, which is then connected to the ribs of the extension as shown in Figure 7c. The pinion drives the rack directly thus pulling the extension in and out of the main wing. It should be noted that the rack is $500 \mathrm{~mm}$ and the fuselage width is $220 \mathrm{~mm}$ so when the extension is fully 
retracted the rack will protrude into the other extension. Therefore, the root section of each main wing has a cut-out to let the rack through when fully retracted. To ensure a robust load path between the extensions and the main wings and minimise friction between them, small ball bearings enclosed in casings fixed to the main wing ribs that would act as wheels for the extension were added. These bearings will act as the only points of contact between the main wing and the extension. Since the only section of the main wing that is always in contact with the extension, regardless of the retraction state, was the outer $280 \mathrm{~mm}$ on both sides (the overlapping distance), the decision was made to have two ribs fitted the bearings: one at the tip of the main wing and one at $280 \mathrm{~mm}$ inboard of the tip of the main wing as shown in Figure $7 \mathrm{~d}$. Each of the ribs would have 3 bearings on both sides (top and bottom) to maximise their load transfer capacity.

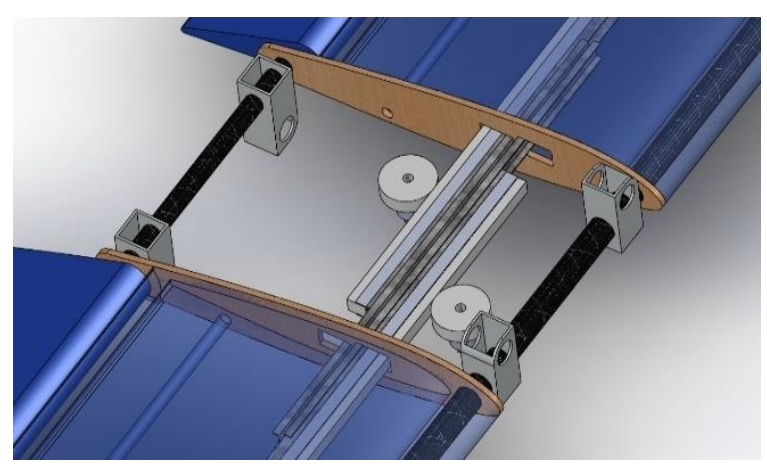

a. Morphing mechanism

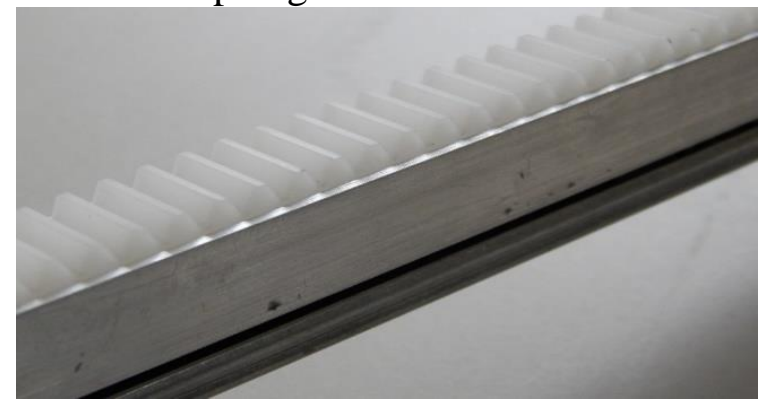

c. Delrin rack housed in the c-channel

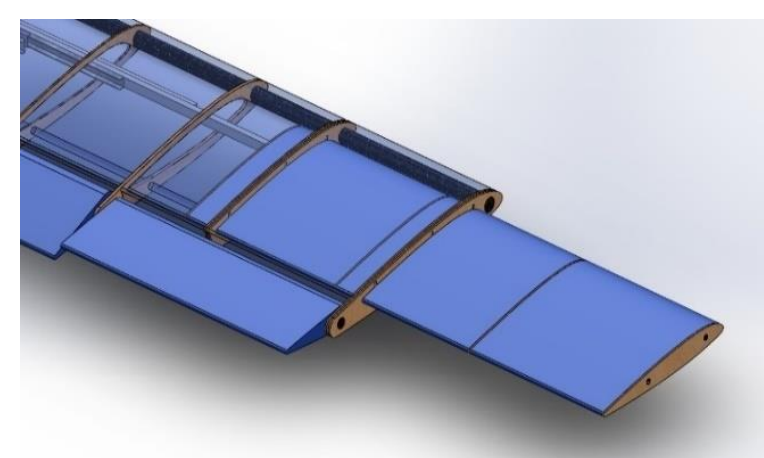

b. Overlapping section

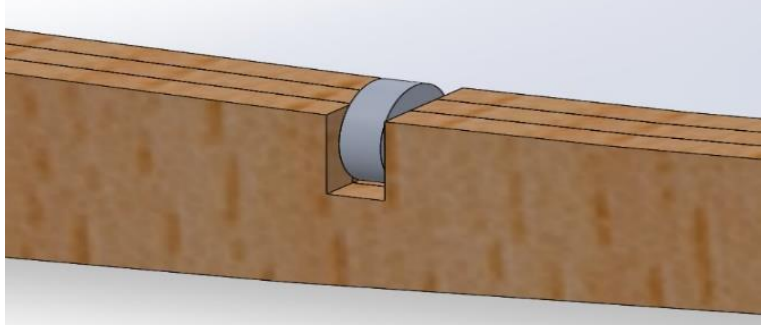

d. Bearings embedded within tip ribs

Figure 7: Layout of the morphing mechanism.

\section{Avionics}

Figure 8 depicts an overall schematic layout of the avionics, showing the various components. 


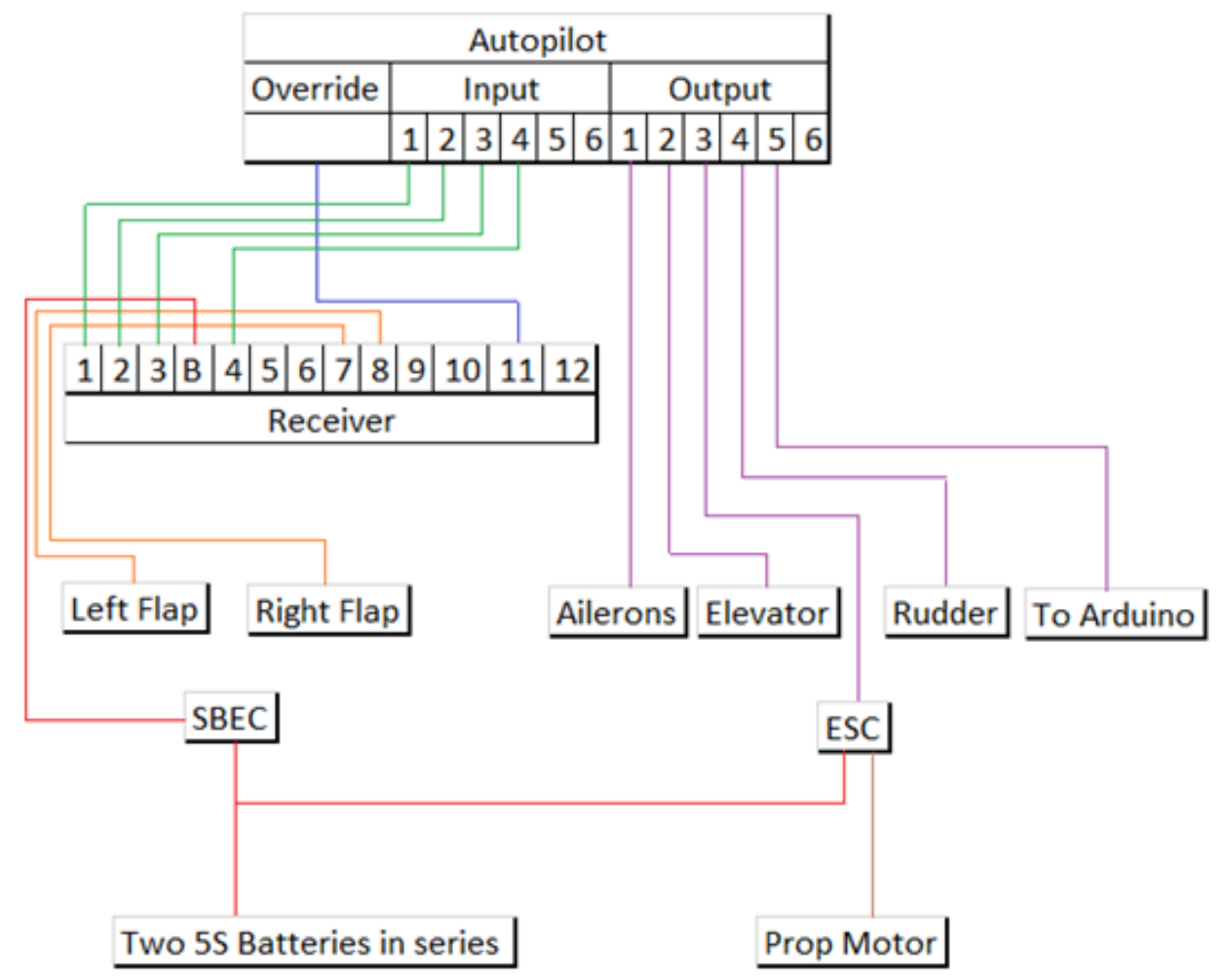

Figure 8: Schematic of avionics on-board.

Stepper motors were chosen to drive the morphing mechanism due to their precise position control and inherent position feedback. The primary tool for controlling the morphing is the on-board SkyCircuits SC2 autopilot system. It initiates morphing by receiving a signal from ground control and outputs a PWM signal through one of its output channels. On the other end of the circuitry, each stepper motor is controlled through the Sparkfun Big Easy motor drive which does not accept PWM signals as input commands. Therefore, an Arduino Uno microcontroller was used to bridge this discontinuity in signal types. Figure 9 shows a schematic of the morphing avionics. 


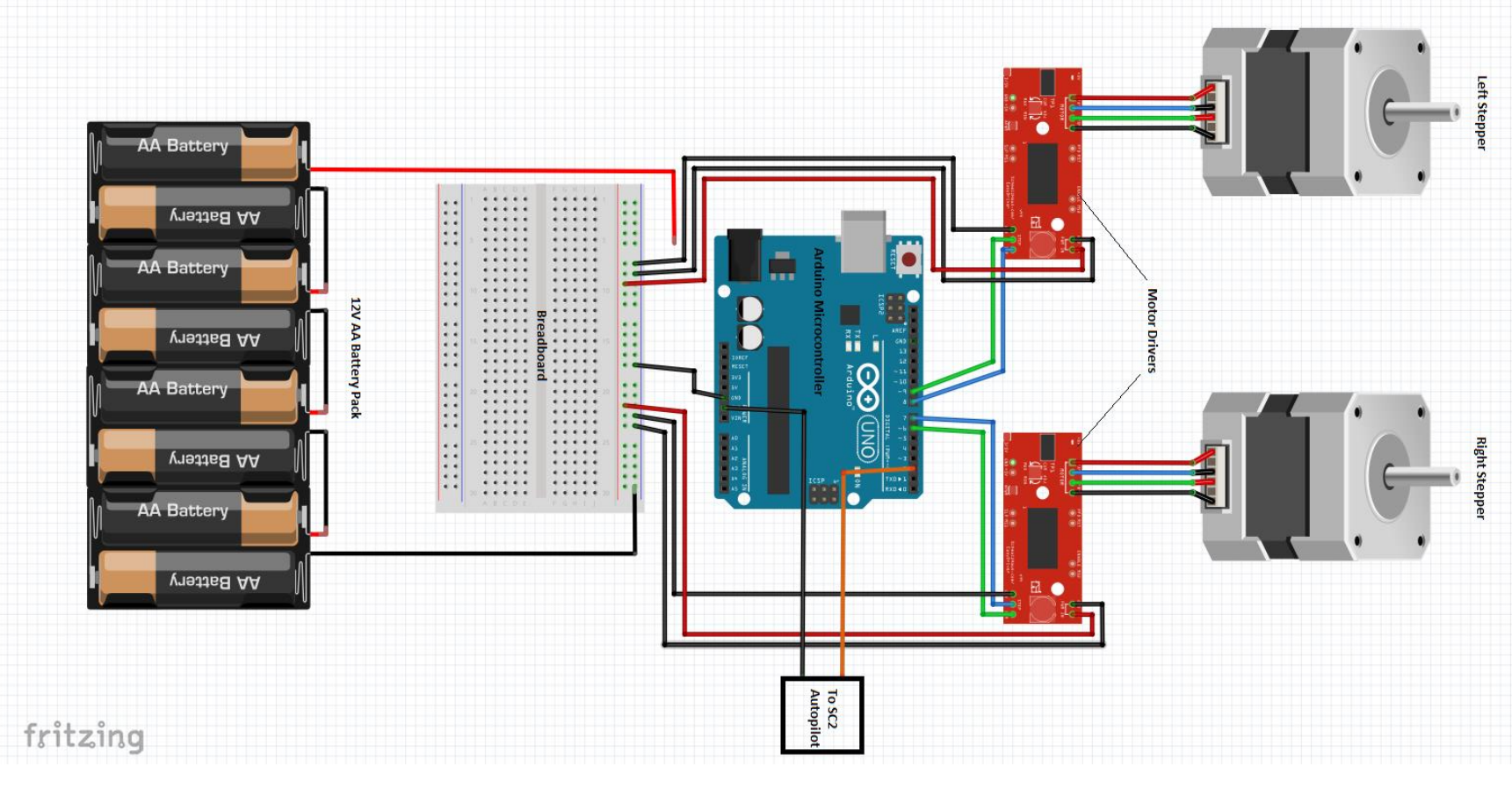

Figure 9: Morphing Avionics.

Using the autopilot's software, the limits of the output channel for morphing were set between 0 and 20 . These linearly interpolated to a PWM signal between 1000 and 2000. Each integer between 0 and 20 represented a different mode. There was a minor fluctuation in the PWM signal therefore bands were used of +/- 25 to ensure the correct mode was accessed. Each mode was responsible for a different action as depicted in Table 2. It was decided that discrete $10 \mathrm{~cm}$ (10\%) extensions would be executed between 0 $(0 \%)$ and $50 \mathrm{~cm}(50 \%)$. The PWM signal was then mapped to its respective mode. The AccelStepper library was used as it enables multiple steppers to be run and provides more precise control of the motors. The number of steps each motor needed to turn to extend $10 \mathrm{~cm}(10 \%)$ was defined and where appropriate, this value was multiplied by the appropriate scale factor up to $50 \mathrm{~cm}$ (50\%) extension. A similar code was also written for asymmetric morphing. Other codes were also written to change the speed of the morphing by altering max speed and acceleration and also a separate code was written to allow extension without retraction (continuous morphing) i.e. increasing in discrete steps from 0 to $50 \%$ without having to retract the wings each time. 
Table 2: Morphing commands.

\begin{tabular}{ccl}
\hline Mode & PWM & Action \\
\hline 0 & 1000 & Reset counters to enable continuous extension \\
\hline 1 & 1050 & Extend $10 \mathrm{~cm}$ \\
\hline 2 & 1100 & Extend $20 \mathrm{~cm}$ \\
\hline 3 & 1150 & Extend $30 \mathrm{~cm}$ \\
\hline 4 & 1200 & Extend $40 \mathrm{~cm}$ \\
\hline 5 & 1250 & Extend $50 \mathrm{~cm}$ \\
\hline 6 & 1300 & Retract to $0 \mathrm{~cm}$ \\
\hline 7 & 1350 & Change to slow speed \\
\hline 8 & 1400 & Change to fast speed \\
\hline 9 & 1450 & Morph both steppers \\
\hline 10 & 1500 & Morph stepper 1 only - Left wing \\
\hline 11 & 1550 & Morph stepper 2 only - Right wing \\
\hline 12 & 1600 & Pull in extensions (small movement) \\
\hline 13 & 1650 & Pull in extensions (large movement) \\
\hline 14 & 1700 & Emergency stop \\
\hline 15 & 1750 & Emergency stop reset \\
\hline
\end{tabular}

Figure 10 shows the avionics and actuation system integrated within the fuselage. It should be noted that the autopilot is mainly used in this paper for the control of the span morphing mechanism whilst the aircraft is controlled manually using the transmitter/receiver. However, in future studies, the Transformer UAV will perform fully autonomous flight using pre-programmed missions in the SC2 autopilot.

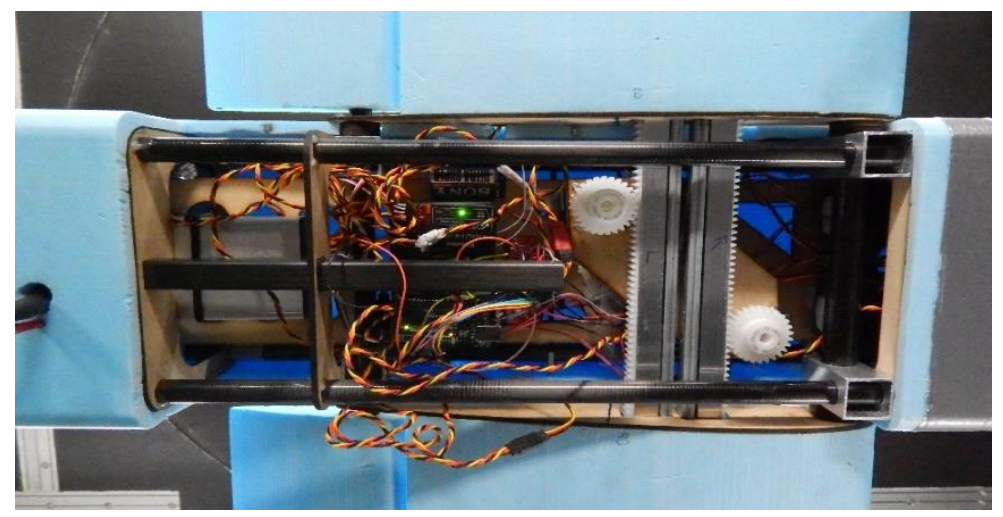

Figure 10: The avionics and actuation system integrated within the fuselage.

\section{Wind Tunnel and Flight Testing}

The subsections below present the testing procedures and the main outcomes. It should be noted that the lift and drag coefficients presented below are obtained using the baseline wing area $(0.9 \mathrm{~m} 2)$ while the pitching moment coefficient is obtained using the baseline wing area and the baseline aerodynamic chord $(0.45 \mathrm{~m})$. The rolling moment coefficient is obtained using the baseline wing area and baseline wingspan 
of $2 \mathrm{~m}$. It is important to fix these geometric parameters used for normalisation of forces and moments to be able to perform unbiased comparison between the coefficients as the wingspan varies.

\section{A. Wind Tunnel Testing}

The UAV was tested in the R. J. Mitchell wind-tunnel, a $3.5 \mathrm{~m} \times 2.4 \mathrm{~m}$ low-speed wind tunnel equipped with an overhead 6-component balance, at the University of Southampton as shown in Figure 16a. All tests were conducted at an airspeed of $15 \mathrm{~m} / \mathrm{s}$ with the propeller/motor on and set at $30 \%$ throttle. It should be noted each test was repeated twice, for the sake of consistency, and the average of the data from both trials is presented below and referred to as a test.

\section{i. Quasi-static Morphing}

Figure 11a shows the variation of lift coefficient with angle of attack for different span extensions. It can be clearly seen that increasing the wingspan increases the lift curve slope of the wing. The stall behaviour of the wing becomes more abrupt as the wingspan increases. Figure 11c shows the lift to drag variation of the wing while Figure 11b shows the total drag coefficient variation with the angle of attack for different span extensions. It is evident that increasing the wingspan enhances the aerodynamic efficiency, especially at low angles where the flow is attached. However, at larger angles of attack, in the region of the stall angle of attack (where viscous and pressure drag are dominant), the larger the wingspan the worse the aerodynamic efficiency is. Figure $11 \mathrm{~b}$ shows the drag polar of the Transformer. It is clear that a larger wingspan at a given lift coefficient generates a lower drag coefficient. Figure 11e shows the variation of the pitching moment coefficient with angle of attack for different span extensions. It can be seen that the slope remains negative ensuring that the UAV is statically stable for all the extensions considered here. It can also be seen that the aircraft's pitching moment is zero between $-1^{\circ}$ and $1^{\circ}$ angle of attack for all extensions. This validates the static stability analysis performed during the design phase. 


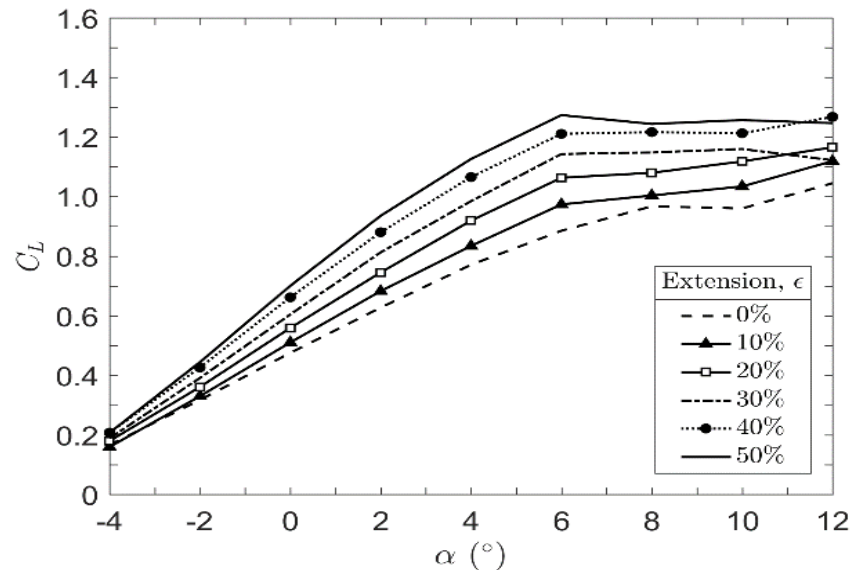

a. Lift Coefficient

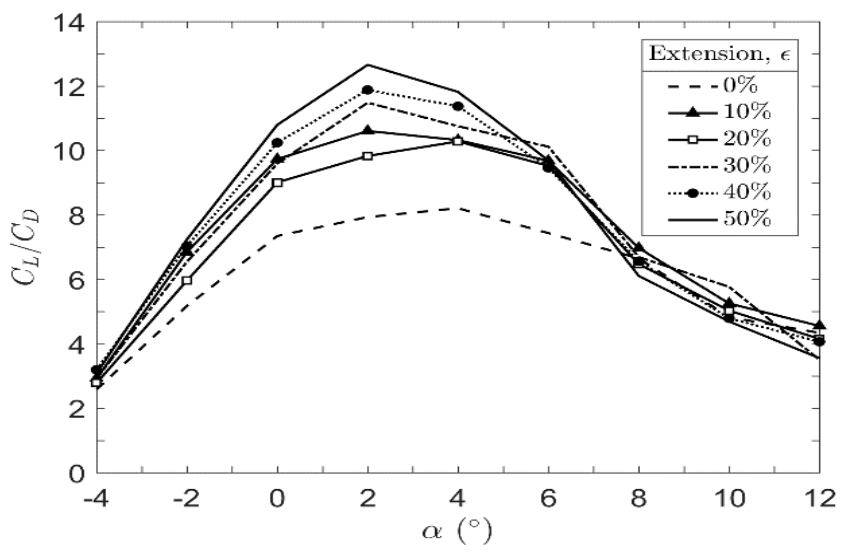

c. Aerodynamic efficiency

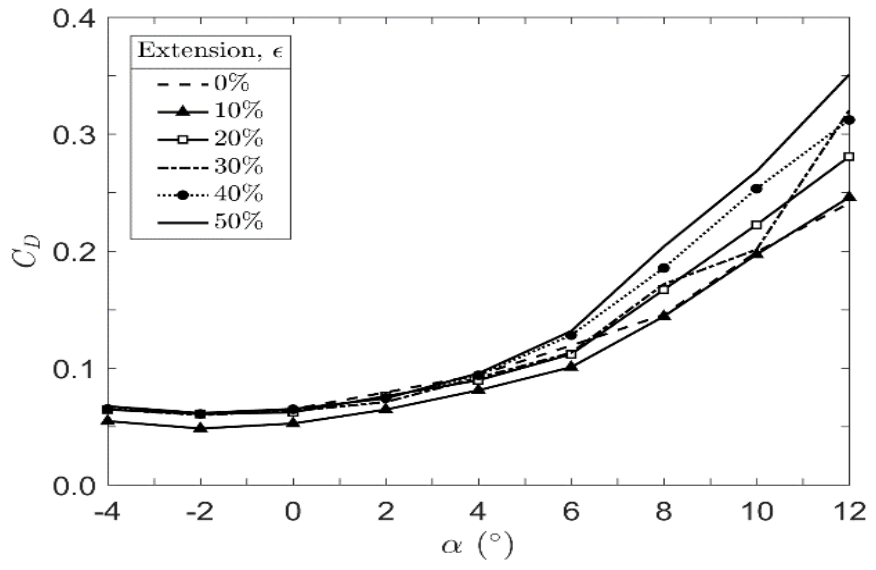

b. Drag Coefficient

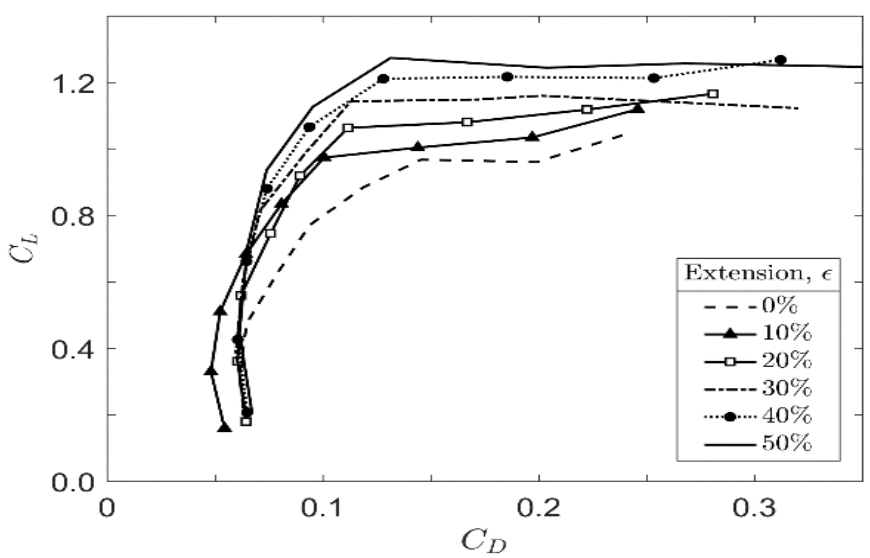

d. Drag polar

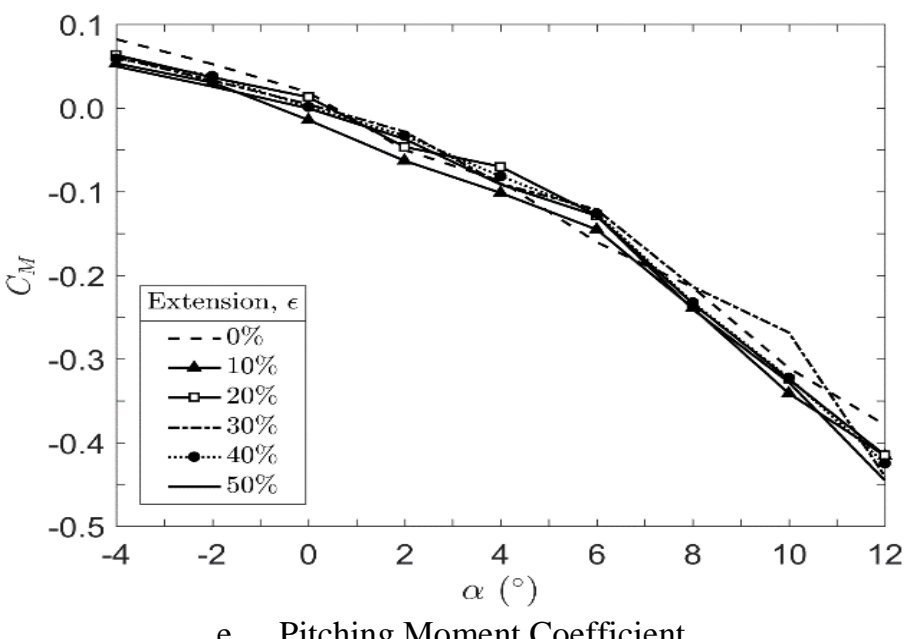

e. Pitching Moment Coefficient

Figure 11: Aerodynamic data on the morphing wing.

Figure 12a shows the variation of rolling moment coefficient with aileron angle for different symmetric span extensions. It is evident that the rolling moment coefficient is almost independent from span extension. 
Similarly, Figure $12 \mathrm{~b}$ shows that the effectiveness of the elevator was not significantly affected by span extension. In fact, extending the wingspan of the UAV, which has a rectangular and unswept wing, does not affect the longitudinal position of the centre of gravity but it slightly affects the tail volume coefficient and slightly increases the wing lift curve slope. However, the overall influence of span extension on the elevator effectiveness can be neglected. A positive aileron angle is defined when the right aileron goes down below the neutral position, and left aileron up for angles above the neutral position. Similarly, a negative elevator angle corresponds to a downward deflection.

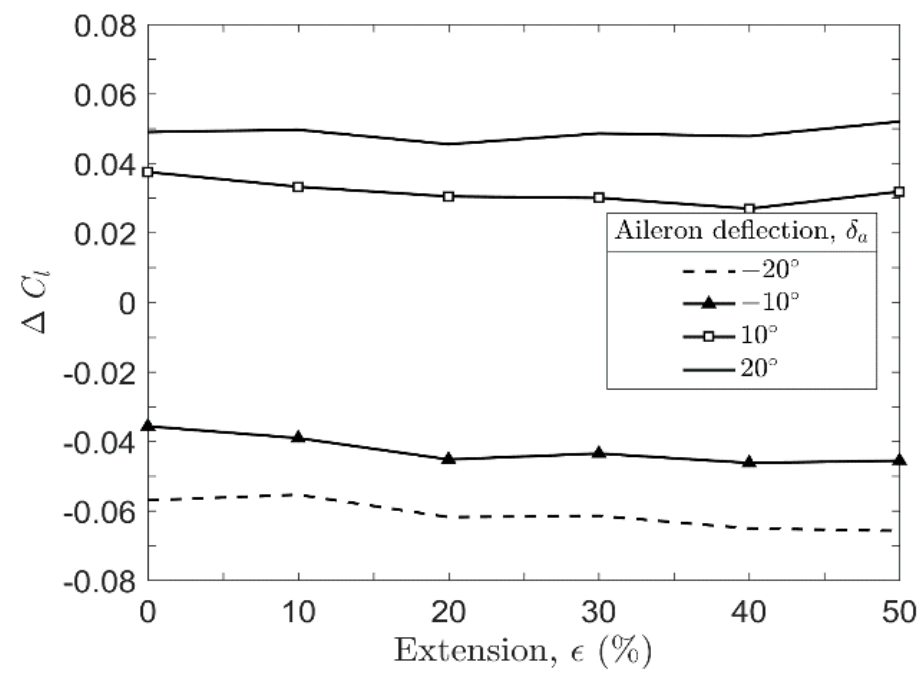

a. Rolling moment coefficent

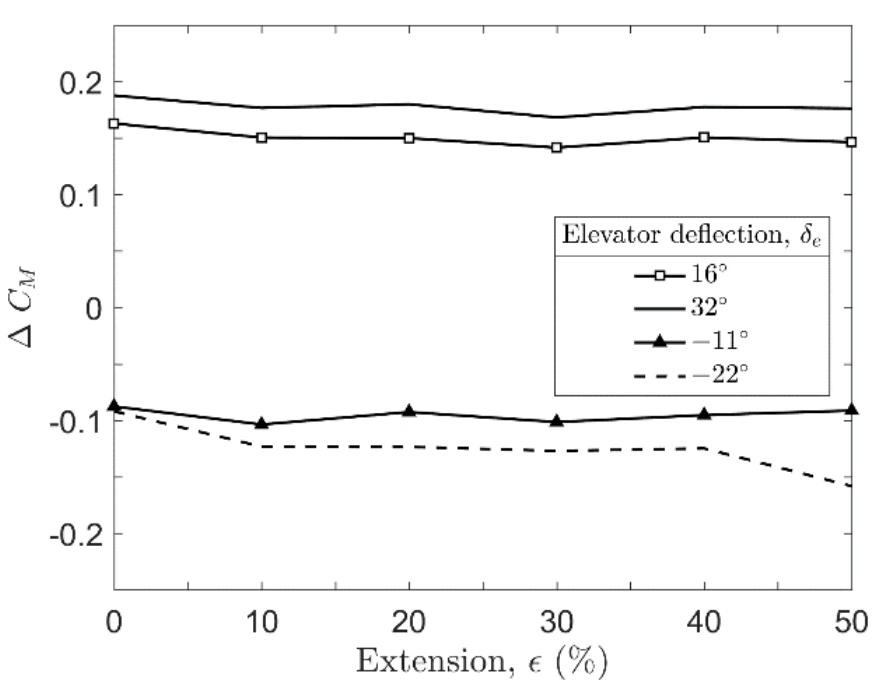

b. Pitching moment coefficient

Figure 12: Effectiveness of control surfaces for different symmetric span extensions.

\section{ii. Dynamic Morphing - Symmetric}

To investigate the dynamic effects of symmetric span extension, different tests with different morphing rates were studied. In the first test, the wing is extended to $50 \%$ at rate of $0.125 \mathrm{~m} / \mathrm{s}$, while in the second test the rate is $0.068 \mathrm{~m} / \mathrm{s}$. As previously noted, there was some degree of noise in the recorded data, which prompted the use of the Lowess method, a smoothing function, to filter out any such disturbances. The function is based on local regression using weighted linear least squares and a 1st degree polynomial model. A time span of not more than $0.5 \mathrm{~s}$ is chosen in order not to bias local trends and lose fidelity of small-scale variations. Figure 13 displays the dynamic variation of aerodynamic forces and efficiency. 


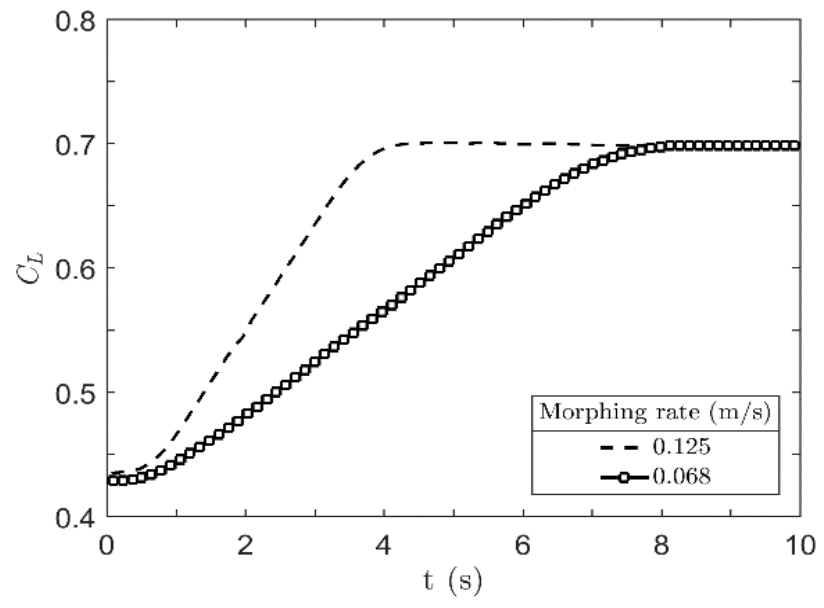

a. Lift

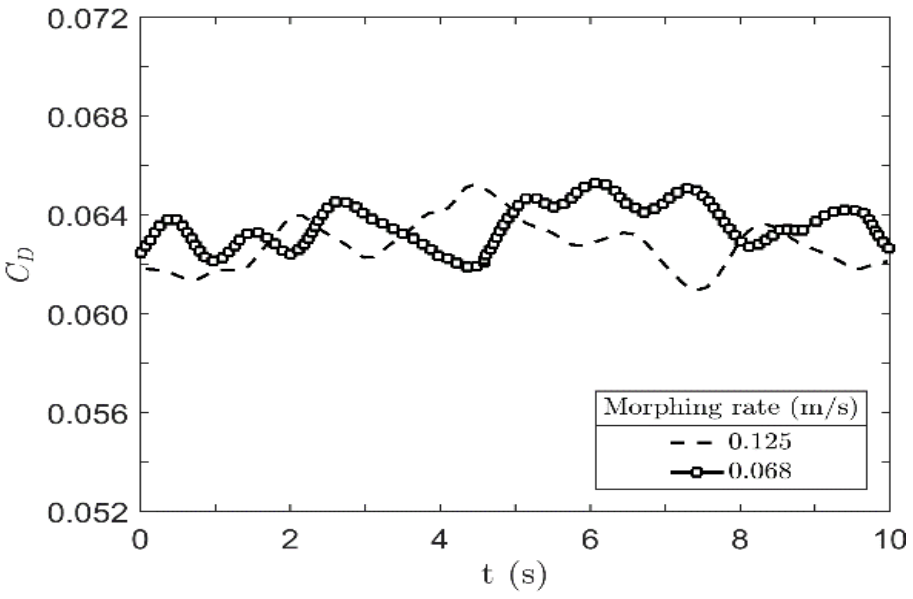

b. Drag

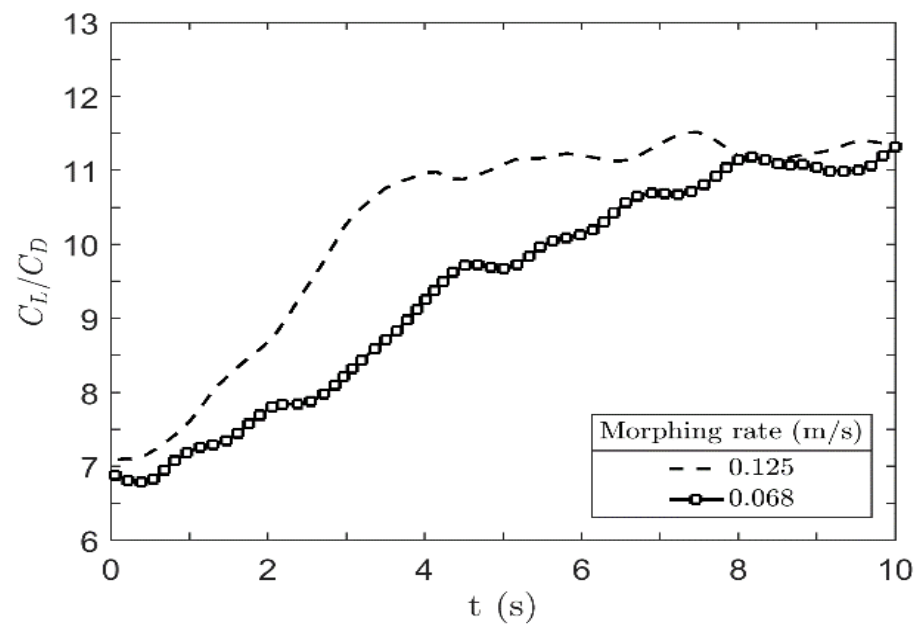

c. Lift-to-drag

Figure 13: Dynamic variation of wing's aerodynamics with symmetric morphing.

From Figure 13a and b, it can be seen that when the extensions start moving the lift drops slightly and then it starts increasing while the drag increases slightly and then it starts decreasing. This can be attributed to the vibration and side forces (due to inertia of the extension) on the balance as the wing extends relatively fast. Following this unsteady behaviour, the lift coefficient settles and start increasing linearly with span extension. The rate of increase in lift coefficient depends mainly on the morphing rate. Figure 13b shows severe variations in the drag force recorded. As stated earlier, all the different morphing rates experience an initial decrease in drag and then a subsequent increase in the final stages of morphing. It can also be observed that an increase in morphing rate results in the reduction in drag being delayed. The pitching 
moment plots were very noisy even after applying the smoothing function and therefore they are not shown here.

\section{iii. Dynamic Morphing - Asymmetric}

Several experiments were carried out to characterise the dynamic response of asymmetric morphing in the wind tunnel. An extension rate of $0.135 \mathrm{~m} / \mathrm{s}$ was used for asymmetric testing. Figure 14 demonstrates the variation of the aerodynamic forces and moments with asymmetric span extension. The portion of the plots that is highlighted in grey represents the duration of the morphing. It was noticed that during the steady state there was some oscillations (at $4.25 \mathrm{~Hz}$ ) in the aerodynamic loads, especially drag and pitching moment.
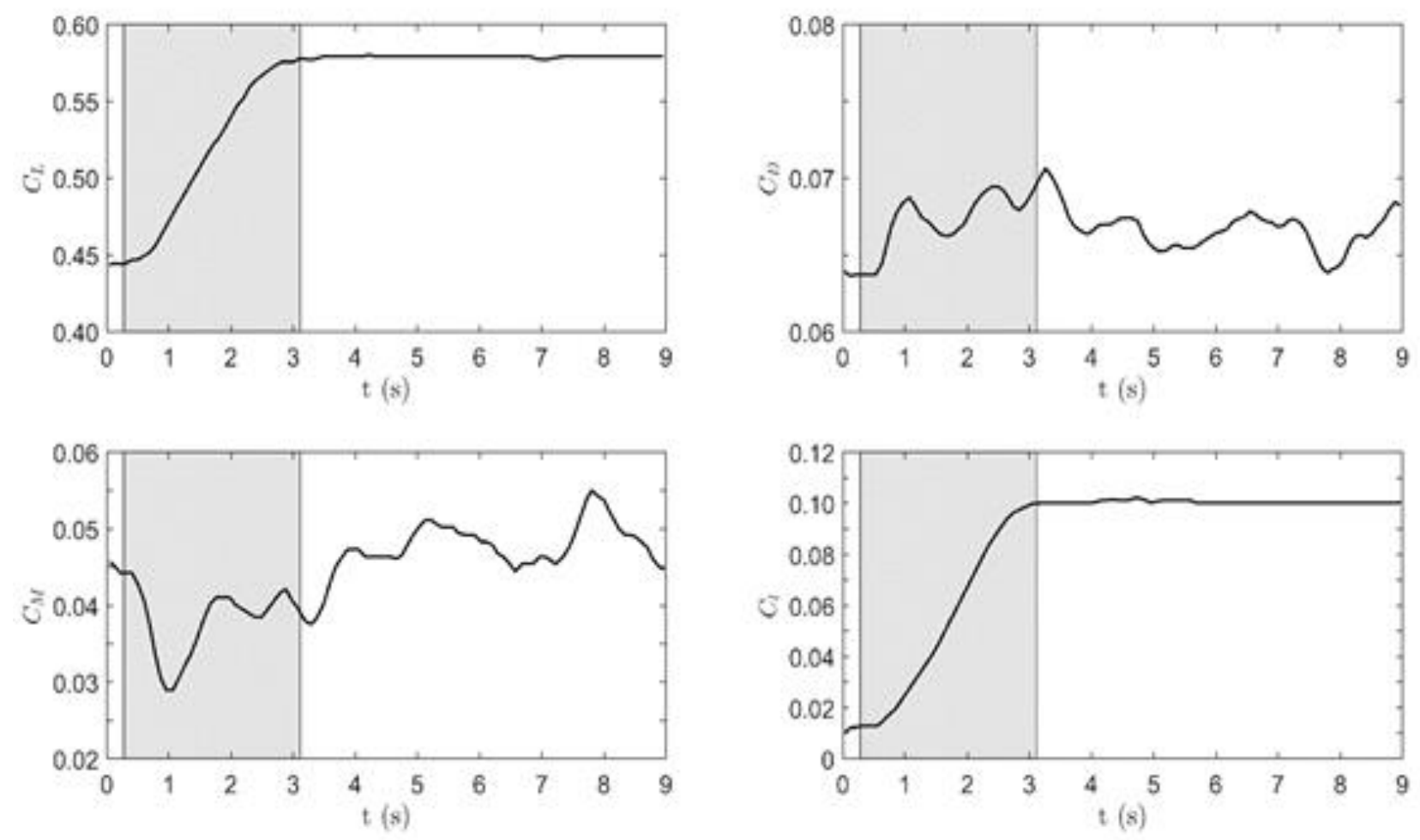

Figure 14: Dynamic response of asymmetric extension from $0 \%$ to $50 \%$.

\section{iv. Rolling Strategies}

The main purpose for investigating the effect of asymmetric wing extension is to assess the ability of span morphing to replace or augment the performance of conventional ailerons. It is evident from Figure 15 that the rolling moment generated by asymmetric span extension can be significantly higher than that generated by conventional ailerons (symmetric and differential), and at roughly $10 \%$ of the drag penalty. This is because the increase in lift on one wing comes from an increase in surface area and aspect ratio, rather than a drastic increase in camber as with ailerons. These results suggest that asymmetric extension may indeed 
be a more efficient way of providing roll control. However, there are a number of issues that need to be considered, the most prominent being the weight of the morphing mechanism. It is estimated that the increase of the mass of the UAV due to the morphing mechanism was roughly $15 \%$. This increase is likely to neutralise any cost benefit coming from more efficient roll control, while increasing the complexity of the design and creating potential reliability issues. Therefore, it is only feasible to use asymmetric span extension as a replacement for ailerons in aircraft that already have span-morphing wings. In addition, adverse yaw would likely be more pronounced due to the large asymmetric drag. A test was conducted to determine the maximum asymmetric extension of the UAV that can be counteracted by ailerons in case one side of the extension gets jammed during symmetric morphing. An additional test involved asymmetrically morphing the wing by discrete steps and adjusting the aileron angle to provide a zero net rolling moment on the force balance.

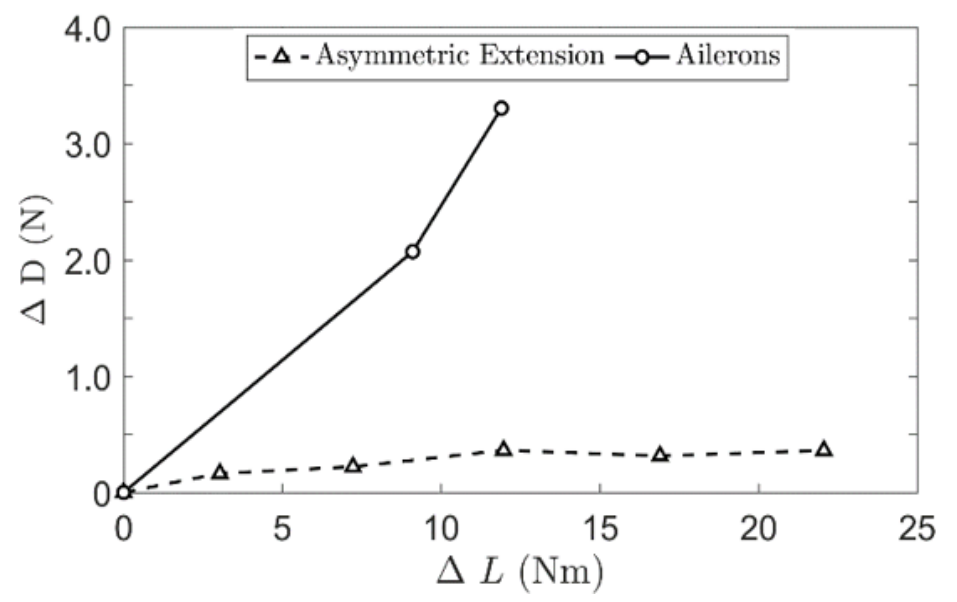

Figure 15: Drag induced by asymmetric extension vs drag induced by ailerons.

From Table 3, it can be seen that with an asymmetric span of $30 \%$ and more, the aircraft is no longer controllable in roll.

Table 3: Aileron deflection required to balance asymmetric extension.

\begin{tabular}{cc}
\hline Extension $(\boldsymbol{\%})$ & $\boldsymbol{\delta}_{\mathbf{a}}\left({ }^{\circ}\right)$ \\
\hline 10 & 15 \\
\hline 20 & 20 \\
\hline 30 & 30 \\
\hline 40 & Uncontrollable \\
\hline 50 & Uncontrollable \\
\hline
\end{tabular}

\section{B. Flight Testing}

Flight testing was carried-out at Draycott Aerodrome in Swindon, United Kingdom. Figure 16b shows the UAV in this configuration during flight-testing. 


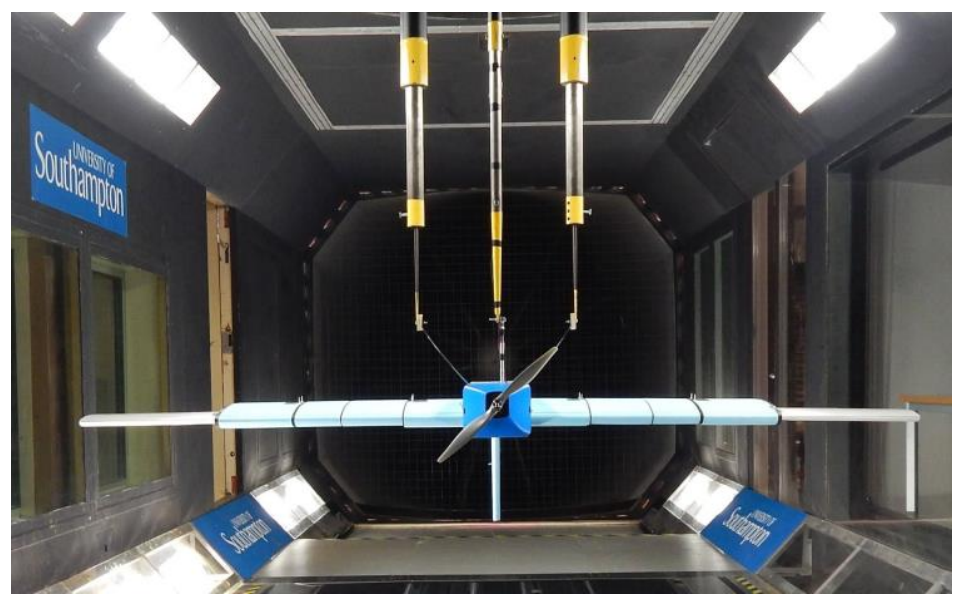

a. Testing in the RJ Mitchel Wind-tunnel.

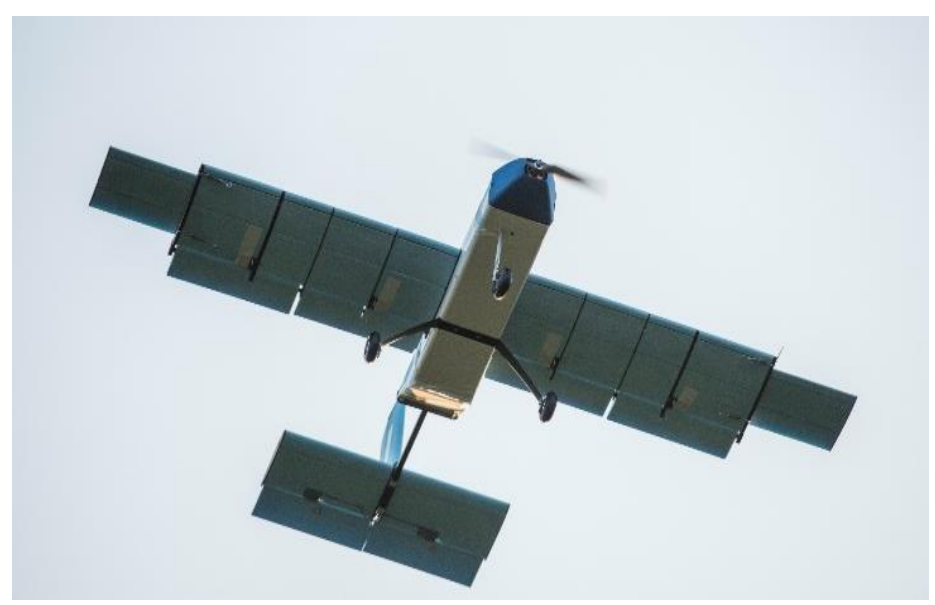

b. Flight testing with wing extended by $30 \%$.

Figure 16: The UAV during wind-tunnel and flight testing.

It should be noted that during flight testing the aircraft was operated remotely from the ground and the autopilot was mainly used to log the data and communicate with the motors and control surfaces. Initially, two flight tests were designed to determine the flight characteristics of the UAV. During these tests, no morphing in flight was performed. In the first test, the wing was fully retracted while in the second test the wing is extended up to $50 \%$ on the ground before take-off. Flight tests three and four were mainly conducted to test the morphing mechanism in flight. During these tests, the SC2 autopilot and ESC were used to gather flight data. The autopilot is capable of recording a wide variety of data, such as Bank and Elevation Angles, Heading, Airspeed, GPS Latitude and Longitude, Acceleration in X, Y and Z directions, Altitude, and Throttle which will be used to analyse the impact of the morphing wing. Due to the difficulties of precisely repeating the same flight path between two tests and also as time constraints prevented repeated flights, instantaneous data from flights with the unextended and extended wing configurations is incomparable and does not provide much insight into the differences between no extension and full extension.

Table 4: Flight test scenarios.

\begin{tabular}{ccc}
\hline Flight no. & Extension type & \% extension \\
\hline 1.0 & No extension & - \\
\hline $2.1,2.2,2.3,2.4,2.5$ & Static/Symmetric & $10,20,30,40$ and 50 \\
\hline $3.1,3.2$ & Dynamic/Symmetric & 10 and 20 \\
\hline $4.1,4.2$ & Dynamic/Asymmetric left wing & 10 and 20 \\
\hline
\end{tabular}




\section{i. Performance: Endurance Test}

It is essential to assess the impact of span morphing on the range and endurance of the UAV. Using the average power data gathered by the ESC as well as the average airspeed recorded by the pitot tube and autopilot, the endurance and range of the first two tests (fully retracted and fully extended) can be estimated. As shown in Table 5, the aircraft with the wings fully achieves $39.1 \%$ increase in endurance and $9.1 \%$ increase in range for a fixed lift coefficient. It should be noted that the full span extension allows the aircraft to fly at a lower speed (due to larger wing area) so that the lift coefficient is the same for both wing's configurations.

Table 5: Variation of range and endurance with span extensions.

\begin{tabular}{lcc}
\hline Variable & Flight 1 - no extension & Flight 2 - full (50\%) extension \\
\hline Battery Capacity $(\mathrm{Wh})$ & 336 & 336 \\
\hline Average Propulsion Power $(\mathrm{W})$ & 885 & 626 \\
\hline Average Airspeed $(\mathrm{m} / \mathrm{s})$ & 17 & 13 \\
\hline Endurance (Minutes) & 23 & 32 \\
\hline Range $(\mathrm{km})$ & 23 & 25 \\
\hline
\end{tabular}

\section{ii. Control: 10\% Asymmetric Extension}

During flight, a 10\% asymmetric span extension was investigated. The left wing took 0.63 seconds to morph by $10 \%$ and the morphing period is highlighted in grey in Figure 17a. The roll response of an asymmetric left wing span extension from $0-10 \%$ is shown in Figure 17a. Prior to morphing, due to servo-related mechanical issues, the UAV required a $7^{\circ}$ asymmetric deflection to trim and maintain a level non-zero bank angle. As expected, upon morphing the left wing, a roll to the right is observed due to the increase in lift of the left wing. The bank rate is calculated as the first time derivative of the variation of bank angle over the morphing period (refer to Table 6). To counter the roll, an initial aileron deflection of $-2^{\circ}$ was applied to level the UAV, which finally settled at approximately $3^{\circ}$ of aileron deflection. Therefore, it is found to a reasonable degree of accuracy that an aileron deflection of approximately $4^{\circ}$ from the neutral position is required to counter the $10 \%$ span asymmetry. 


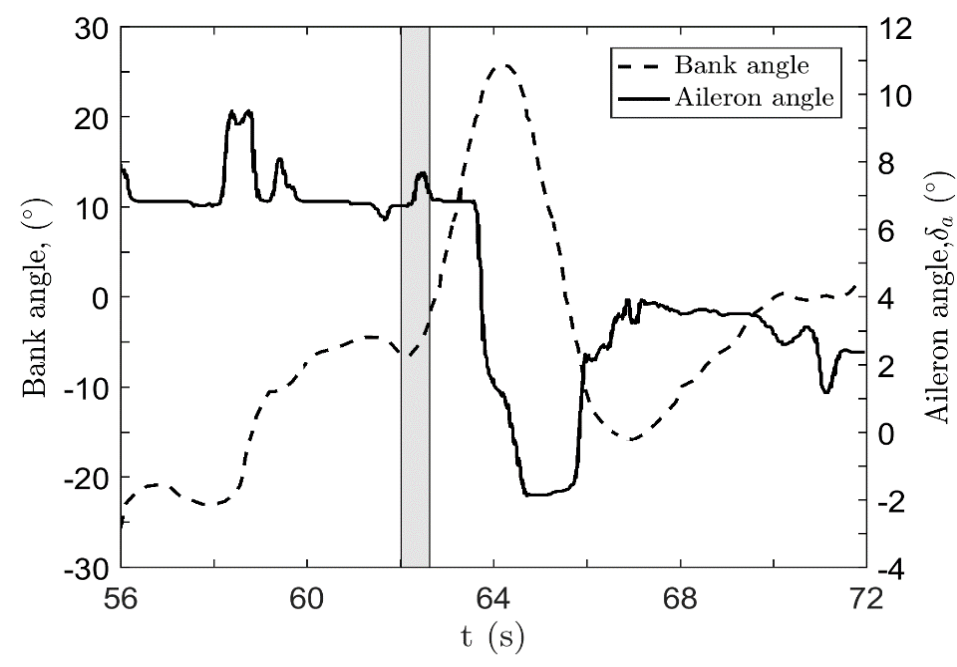

a. During a 0-10\% asymmetric left-wing extension.

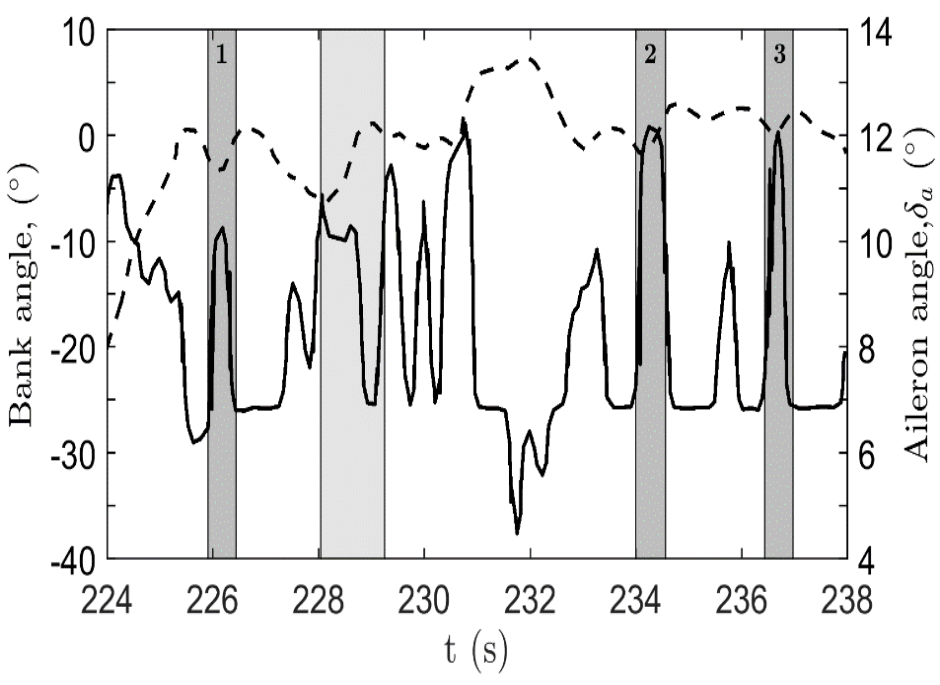

b. During a 10-30\% symmetric wing extension.

Figure 17: Variation of bank and ailerons angles during flight testing.

Table 6: Bank rate due to 0-10\% asymmetric left-wing extension.

\begin{tabular}{ccc}
\hline Time $(\mathbf{s})$ & Bank Angle $\left({ }^{\circ}\right)$ & Bank Rate $\left({ }^{\circ} / \mathbf{s}\right)$ \\
\hline 62.9 & 2.45 & 23.25 \\
\hline 63.7 & 21.05 & \\
\hline
\end{tabular}

\section{iii. Control: 10-30 \% Symmetric Extension}

A 10-30\% symmetric extension case during flight was investigated. Morphing started at 228 seconds and lasted approximately 1.26 seconds as shown in Figure 17b. During the symmetric morphing test, a series of three rapid aileron deflections were performed. These have been identified and highlighted in dark grey boxes in Figure 17b. Such actions enabled a thorough study of the roll response and authority before and after wing extension to be carried out. Data logging of aileron deflection angles allowed comparisons of bank responses from aileron deflections. It is important to note that this roll rate analysis should only be used a qualitative guide to roll authority as insufficient data and uncertainties limit an accurate quantitative study. The first rapid aileron deflection occurred 2 seconds before morphing with an aileron rate of $16.52 \%$ s. The span here is equivalent to that of $10 \%$ symmetric span extension. This deflection produced a bank rate of $13.47 \%$ s approximately 0.2 seconds later (Table 7 ).

Table 7: Aileron effectiveness at $10 \%$ span extension.

\begin{tabular}{cccccc}
\hline Time $(\mathbf{s})$ & Aileron Angle $\left({ }^{\circ}\right)$ & Aileron Rate $\left({ }^{\circ} / \mathbf{s}\right)$ & Time $(\mathbf{s})$ & Bank Angle $\left({ }^{\circ}\right)$ & Bank Rate $\left({ }^{\circ} / \mathbf{s}\right)$ \\
\hline 226 & 7.04 & 16.52 & 226.2 & -3.61 & 13.47 \\
\cline { 1 - 2 } 226.2 & 10.35 & & 226.5 & 0.43 & \\
\hline
\end{tabular}

The second and third rapid aileron deflections occurred approximately 6 and 8 seconds after morphing, where the wing span is equivalent to $30 \%$ extension, with aileron rates of $26.63 \%$ and $23.80 \%$ s respectively 
(Table 8). In contrast to the aileron rate, the bank rate showed a significant reduction (almost 50\%) for the extended wing configuration.

Table 8: Aileron effectiveness at $30 \%$ span extension.

Second aileron deflection

\begin{tabular}{|c|c|c|c|c|c|}
\hline Time (s) & Aileron Angle ( ${ }^{\circ}$ ) & Aileron Rate ( $\%$ s) & Time (s) & Bank Angle $\left(^{\circ}\right)$ & Bank Rate $(\% / s)$ \\
\hline 234 & 6.83 & \multirow{2}{*}{26.63} & 234.2 & -1.86 & \multirow{2}{*}{7.72} \\
\hline 234.2 & 12.16 & & 234.5 & 0.79 & \\
\hline \multicolumn{6}{|c|}{ Third aileron deflection } \\
\hline 236.4 & 6.83 & \multirow{2}{*}{23.80} & 236.7 & 0.03 & \multirow{2}{*}{7.72} \\
\hline 236.6 & 11.60 & & 237 & 2.35 & \\
\hline
\end{tabular}

Even though larger aileron deflection normally increases roll response rate, the fact that the bank rate experiences a decay confirms the reduction in roll authority for extended wings. This is mainly due to the fact that the rolling inertia of the aircraft doubles as the wing is fully extended and the roll damping increases significantly resulting in a sluggish response to aileron's input.

\section{Conclusion}

This paper presented the development of the Transformer UAV, a multi-mission aircraft capable of symmetric and asymmetric span morphing A detailed overview on the design, manufacturing and integration of the UAV is provided. The UAV utilises a novel span morphing concept that is based on a rack and pinion mechanism. The concept is multifunctional where the actuation mechanism acts as the main load bearing component in the wing. The mechanism allows both symmetric and asymmetric span extensions of up to $50 \%$. The UAV is utilised as a flying demonstrator to assess the impact of symmetric and asymmetric morphing on the flight performance and flight mechanics. Both quasi-static and dynamics testing of the aircraft in the wind-tunnel and in flight were carried out. The quasi-static testing confirmed the results of earlier studies suggesting that symmetric span extension enhances the aerodynamic efficiency and hence the endurance of the aircraft. It also showed that asymmetric span extension can provide large rolling moment especially at high dynamic pressures with a lower drag penalty when compared to conventional ailerons. The dynamic symmetric span extension showed that at the start morphing, the lift drops slightly and then it increases while the drag increases slightly and then it starts decreasing. Following that, the lift coefficient increased linearly with span extension and the rate of increase depended mainly on the morphing rate. Furthermore, asymmetric dynamic testing showed that ailerons are faster than asymmetric span extension in generating the desired roll authority. This indicates that asymmetric span extension can be used to augment the performance of conventional ailerons but cannot fully replace them. It was also noticed that the roll/bank rate from aileron deflections reduces significantly as the wingspan 
increases. In summary, this paper has demonstrated that span morphing is an effective technology capable of enhancing the aerodynamic efficiency of the aircraft and allowing multi-mission capability.

\section{Acknowledgement}

This material is based on work supported by the Air Force Office of Scientific Research under Award

Number FA9550-15-1-0422. The authors like to thank Dr Mario Ferraro and the GDP43 (1516) Team for their contribution and continuous support throughout the project.

\section{References}

Ajaj, R.M., Beaverstock C.S., and Friswell M.I. (2016a) "Morphing Aircraft: The Need for a New Design Philosophy". Aerospace Science and Technology, 49, February 2016, 154-166.

Ajaj, R.M., Friswell, M.I., Bourchak, M., \& Harasani, W. (2016b) "Span Morphing using the GNATSpar Wing". Aerospace Science and Technology, 53, June 2016, 38-46.

Ajaj, R.M., Friswell, M.I., Saavedra Flores, E.I., Keane, A.J., Isikveren, A.T., Allegri, G., and Adhikari, S. (2014) "An integrated conceptual design study using span morphing technology" Journal of Intelligent Material Systems and Structures, 25, (8), 989-1008. (doi:10.1177/1045389X13502869).

Ajaj, R.M., Friswell, M.I., Saavedra Flores, E.I., Little, O., and Isikveren, A.T. (2012) "Span Morphing: A Conceptual Design Study," 20th AIAA/ASME/AHS Adaptive Structures Conference, 23-26th April, Honolulu, Hawaii, USA, AIAA-2012-1510.

Ajaj, R.M., Saavedra Flores, E.I., Friswell, M.I. and DiazDelaO, F.A. (2014) "Span morphing using the compliant spar" Journal of Aerospace Engineering, 1-13. (doi:10.1061/(ASCE)AS.19435525.0000442).

Ajaj, R.M., Saavedra Flores, E.I., Friswell, M.I., Allegri, G., Woods, B.K.S., Isikveren, A.T. and Dettmer, W.G. (2013) "The Zigzag wingbox for a span morphing wing," Aerospace Science and Technology, 28, (1),364-375. (doi:10.1016/j.ast.2012.12.002).

Bae, J.S., Seigler, T. M., and Inman, D. J. (2005) "Aerodynamic and Aeroelastic Characteristics of a Variable-Span Morphing Wing," Journal of Aircraft, Vol. 42, No. 2, pp. 528-534.

Barbarino, S., Bilgen, O., Ajaj, R.M., Friswell, M.I., and Inman, D.J. (2011) “A Review of Morphing Aircraft," Journal of Intelligent Material Systems and Structures, 22(9), 823-877, June 2011.

Blondeau J. and Pines D. (2007) "Design and Testing of a Pneumatic Telescopic wing for Unmanned Aerial Vehicles," AIAA, Journal of Aircraft, 44(4).

CASR Part 21 (2011), "Civil Aviation Safety Authority: Certification and Airworthiness Requirements for Aircraft". (https://www.southampton.ac.uk/ jps7/D8\%20website/UAV certification\%20stds.pdf)

Deperrois A. (2014), "Guidelines for XFLR5 v6.03: Analysis of foils and wings operating at low Reynolds number". Technical document, September 2010. (http://www.xflr5.com/xflr5.htm).

Weisshaar, T.A. (2006) "Morphing Aircraft Technology - New Shapes for Aircraft Design," RTO-MPAVT-141, Neuilly-sur-Seine, France. 